Neuroradiology 8, $141-147$ (1974)

(C) by Springer-Verlag 1974

\title{
Vertebrobasilar Arterial Occlusions in Children
}

\author{
R. E. Latchaw*, J.F. Seeger and T. O. Gabrielsen \\ Department of Radiology, University of Michigan Medical Center, Ann Arbor, Michigan 48104, USA \\ Received: July 18, 1974
}

Summary. Three children with angiographically confirmed, sudden thrombosis involving the vertebro basilar arterial system are presented. Ten previously reported cases are reviewed with particular regard to possible etiologies. Vertebral artery trauma at the atlantoaxial level is suspected as one important cause.

\section{Occlusions artérielles vertébrobasilaires chez l'enfant}

Résumé. Les auteurs rapportent trois cas d'enfants présentant une trombose soudaine du système artériel vertébrobasilaire, confirmée angiographiquement. $\mathrm{Ils}$ revoient dix cas antérieurs, en particulier du point de vue éthiologique. Le traumatisme de l'artère vertébrale au niveau de la charnière cervico-occipitale semble être l'une des causes principale.

Vertebro-basiläre Arterien-Verschlüsse in der Kindheit

Zusammenfassung. 3 Kinder mit einer angiographisch nachgewiesenen plötzlich aufgetretenen Thrombose des vertebro-basilären Systems werden geschildert, gleichzeitig wird ein Utborblick über weitere 10 vorher veröffentlichte Fälle gegeben. Diskussion der möglichen Ätiologie. Es wird darauf verwiesen, daß ein Trauma der A. vertebralis in Höhe des atlanto-axialen. Gelenkes eine wichtige Ursache sein kann.
Vertebrobasilar arterial occlusions in adults are usually due to atherosclerosis and are well known both pathologically and angiographically $[1,2,9,12,16]$. Vertebrobasilar occlusions in children are uncommon, and reports with angiographic illustrations of such cases are rare $[3,4,6,9,10,12,13,15]$. The main purpose of this paper is to report three children with angiographic demonstration of vertebrobasilar occlusions. The pertinent literature will be reviewed, and possible etiologies will be discussed.

\section{Report of Cases}

Case 1. T.R. was a 7 year old boy who suddenly felt dizziness, headache, and stiffness of the neck while in school. There was no definite history of trauma. On admission to University of Michigan Medical Center (UMMC) the same day, he was lethargic and irritable, complained of double vision, and had slurred speech. Nourological examination revealed a right hemiparesis, generalized hyperactive reflexes, a Babinski sign on the right, right central facial palsy, and right sided extinction on sensory examination. The oropharynx was erythematous. The physical examination was otherwise normal. There was no evidence of heart disease. He had had a slight nonproductive cough without fever for about two weeks prior to hospitalization.

Skull roentgenograms were normal. Lumbar puncture showed an opening pressure of $130 \mathrm{~mm}$ CSF with fluid analysis as follows: protein $18 \mathrm{mgm} \%$, sugar $82 \mathrm{mgm} \%$, $8 \mathrm{RBCs} / \mathrm{mm} 3$, no $\mathrm{WBCs}$, and no bacterial growth.

* This study was supported in part by a Special Fellowship in Neuroradiology (R.E.L.), 5F11NS02476-02, from the National Institute of Neurological Diseases and Stroke.
Left common carotid angiography performed one day after hospital admission showed basilar and left posterior cerebral artery occlusions (Fig. 1a and b). The basilar artery occlusion was confirmed by selective right vertebral angiography (Fig. $1 \mathrm{c}-\mathrm{e}$ ) which also suggested the presence of an abnormality in the high cervical portion. of the right vertebral artery (Fig. $1 \mathrm{c}$ and $\mathrm{d}$ ).

Subsequent blood studies demonstrated a prothrombin time of $63 \%$ and slightly prolonged partial thromboplastin and thrombin times. While laboratory studies for possible underlying collagen disease were not performed, there was never any clinical evidence of such a possibility.

During the first forty-eight hours following hospital admission the patient became progressively decerebrate, with multiple cranial nerve deficits. His level of consciousness gradually improved again and he was discharged from the hospital 10 weeks later with a flaccid quadriplegia. Followup examination $4 \frac{1}{2}$ years later demonstrated a spastic quadriplegia. He could not speak but was mentally alert and communicated by blinking his eyes.

Case 2. T.K. was an eleven year old boy who was in good health until he struck the right temporal region of his head while playing football. He was unconscious for one or two minutes but apparently recovered and continued to play. The next day he was lethargic, diaphoretic, and had a fever. He was thought to have the "flu". However, he had a convulsive seizure on the following day and was semicomatose thereafter. This prompted admission to a local hospital. Examination showed left hemiparesis and left central facial palsy. Lumbar puncture was done on the same day, with fluid analysis as follows: protein $27 \mathrm{mgm} \%$, sugar $65 \mathrm{mgm} \%, 7 \mathrm{RBCs} / \mathrm{mm}^{3}$, no WBCs, nonreactive VDRL, and no bacterial growth. A chest $X$ ray four days later revealed bilateral bronchopneumonia. The patient was treated with antibiotics, steroids, phenobarbital, and dilantin. He remained semicomatose for approximately two weeks but gradually became more alert. After another week of intermittent difficulty with speech and residual left hemiparesis, a right carotid arteriogram was done, which was considered normal. He was discharged a few days afterwards but was referred to UMMC three weeks later for further evaluation. 
The mother described occasional "shaking" movements involving the left side of the body but no generalized convulsive seizures. Examination showed left central VII and XII cranial nerve palsies, left hemiparesis, hyperactive reflexes in both legs, and a left Babinski sign. He exhibited inappropriate behavior, with occasional bursts of uncontrollable laughter.

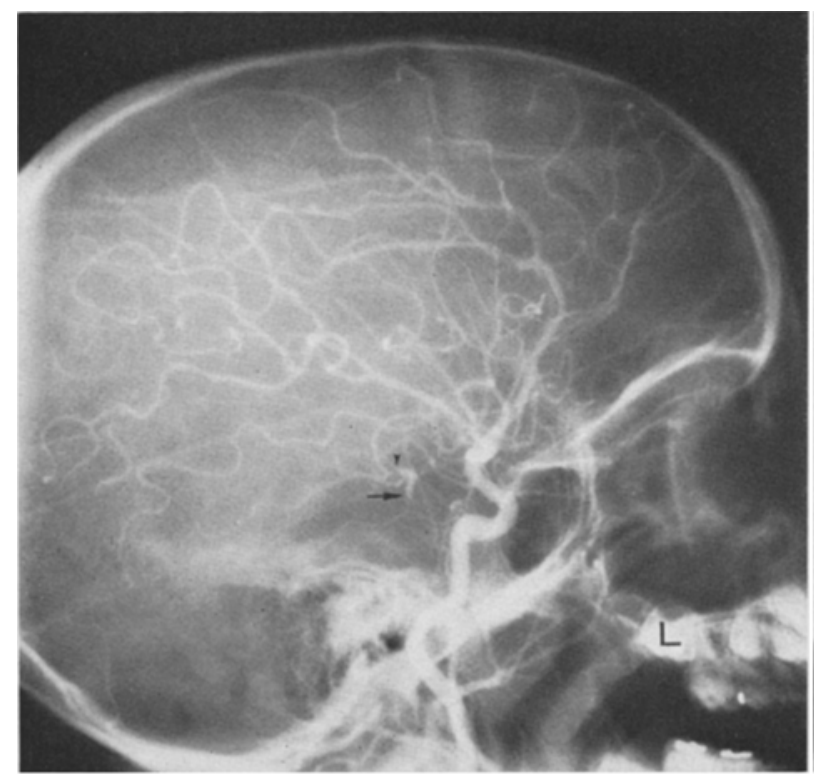

$\mathbf{a}$
Skull roentgenograms, electrocardiography, electroencephalography, brain scan, urine test for homocystinuria, serum protein electrophoresis, serum lipid studies, and partial thromboplastin time were normal. Prothrombin time was $41 \%$. Electron microscopic evaluation of blood platelets showed an increased number of "activated" types and a large number of platelet aggregates.

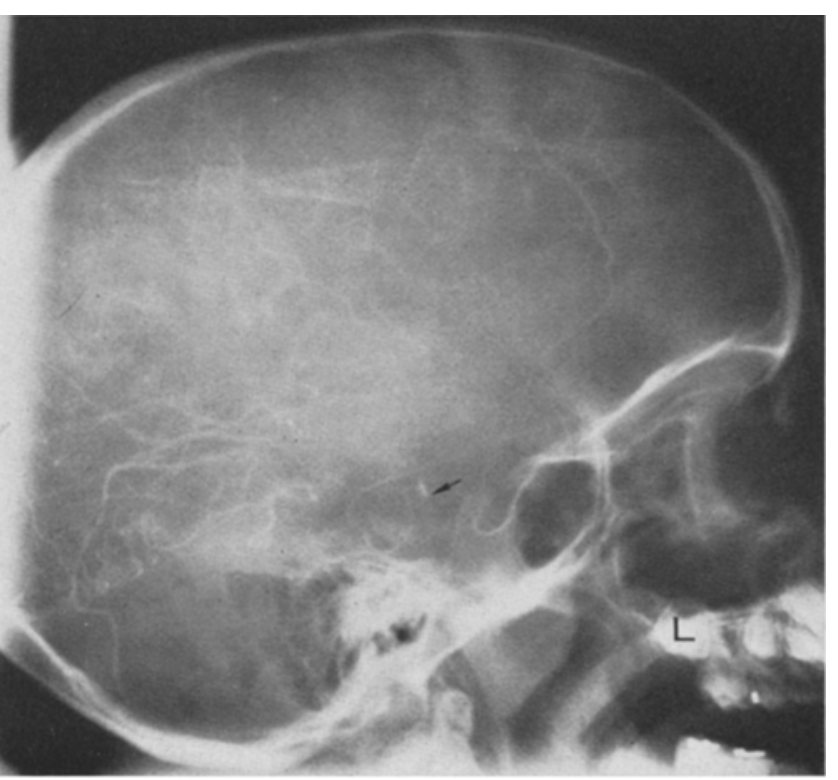

b

Fig. 1. a) Left common carotid angiogram. The distal basilar artery (arrow) is filled from the left posterior communicating artery. The proximal left posterior cerebral artery is occluded (arrowhead). b) Later phase. Contrast material persists in the basilar tip (arrow). There is collateral filling of left posterior cerebral artery branches. (cand d) Selective right vertebral angiogram, frontal and lateral views. The basilar artery is occluded near its origin (arrow). There is focal narrowing of the right vertebral artery at the $\mathrm{C}_{2}$ level (large arrowhead). Occlusion of the left vertebral artery at the $\mathrm{C}_{2}$ level (crossed arrow) was suggested by the pattern of reflux from right to left vertebral arteries on serial films and muscular collateral right-to-left flow (small arrowheads). e) Later phase. Contrast gradually reaches the mid-portion of the basilar artery and outlines several intraluminal filling defects (arrows). There is collateral flow to the superior cerebellar artery from branches of the left posterior inferior cerebellar artery

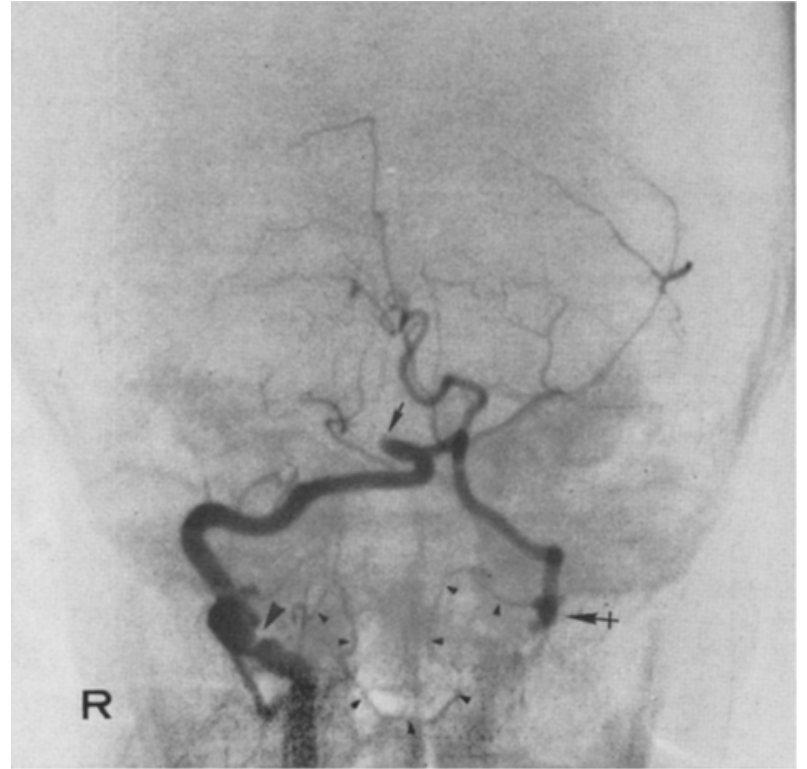

c

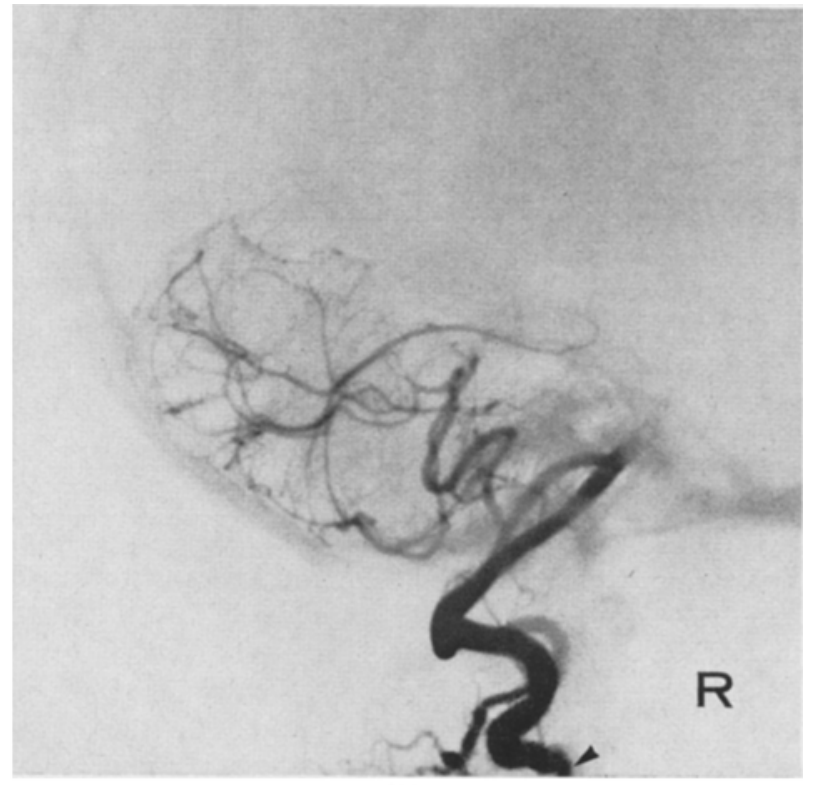

d 
Transfemoral bilateral internal carotid and right vertebral angiographies were performed about seven weeks following the onset of the patient's illness. Occlusions were found in the basilar artery (Fig. $2 a$ and $b$ ) and left vertebral artery (Fig. $2 \mathrm{~b}$ and $\mathrm{c}$ ). There was marked narrowing of the proximal portion of the left posterior cerebral artery (Fig. 2d), with more peripheral branch

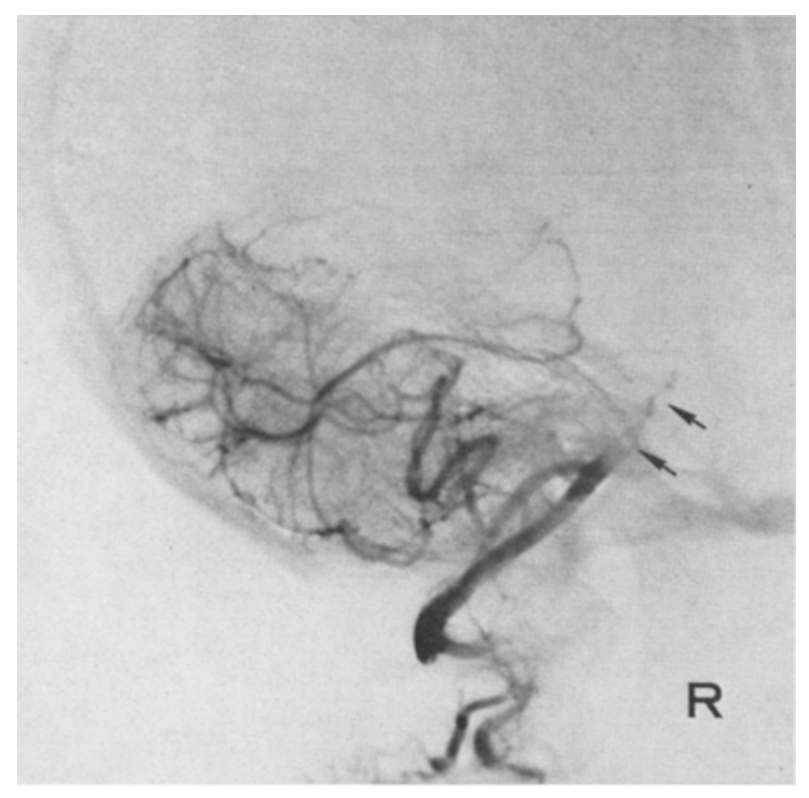

e

occlusions distal to the junction with the posterior communicating artery and collateral flow into terminal branches (not illustrated). Irregularities in right posterior cerebral artery branches (Fig. 2e) and evidence of collateral flow into terminal branches (not illustrated) were also noted.

Two years later the child was attending regular school but performing at the bottom of his class. He still showed mild left homiparesis and spasticity, hyperactive reflexes in both lower extremities, mild left central facial palsy and occasional episodes of inappropriate laughter.

Case 3. K.H. was a twelve year old boy who was in good health until he fell from a slowly moving car. He sustained a head injury which was thought to be trivial. During the subsequent week he developed increasing headache, nausea, vomiting, and lethargy which progressed to coma. On admission to UMMC (in 1958) he had left hemiparesis, bilateral Babinski signs, decerebrate posturing, and probable papilledema. Emergency placement of multiple, bilateral burr holes in the skull disclosed no evidence of intracranial hematoma. Limited ventriculography showed no local mass or hydrocephalus. The CSF was xanthochromic.

The patient gradually regained consciousness and became alert but was emotionally labile. The diagnostic considerations were encephalitis or a vascular injury affecting the brain stem. On discharge from the hospital one month postoperatively the patient had intact cranial nerves, good motor strengh in all extremities, bijateral hyperreflexia (more marked on the right), bilateral ankle clonus and a right Babinski sign. Sensory examination and finger-to-nose testing were normal.

Almost fifteen years later, at the age of 26 years, the patient was readmitted to UMMC complaining of low back pain, which was considered due to spondylolysis of $\mathrm{I}_{5}$. He also complained of occasional parasthesias in the right arm. Examination demonstrated dysarthric speech, spastic gait, generalized hyperreflexia, increased muscle tone in the legs, a Babinski sign on the right and possibly on the left, and mild left dysdiadochokinesis.

Transfemoral, bilateral internal carotid and bilateral vertebral angiographies showed occlusions of the basilar and left vertebral arteries (Fig. 3a-d).

Comment: There can be little doubt that the arterial occlusions in this patient occurred at the age of 12 years, almost 15 years prior to the angiography.

\section{Discussion}

A review of the literature disclosed only ten previous cases of angiographically confirmed, sudden thrombosis involving the vertebrobasilar arterial system in children under the age of 18 years $[3,4,6,9,10$, $12,13,15]$. One of these was a 10 year old child referred to by Moscow and Newton [9], but the angiogram was not shown. In two of the remaining nine cases, essentially no clinical information was given, although a lateral view of the vertebral angiogram was demonstrated in each case $[6,12]$. Because all ten patients apparently survived the thrombotic episode, the etiology in most cases could not be established. One of the three cases reported by Ouvrier and Hopkins [10] was clearly an example of basilar artery embolism secondary to bacterial endocarditis.

Fowler [5] presented autopsy findings in two children who died five days and ten weeks respectively following the sudden onset of coma. The first child, with septicemia due to burns, had distal basilar artery thrombosis, which in all likelihood was secondary to a demonstrated inflammatory process in the wall of the basilar artery. In the second child, previously healthy, the cause of thrombosis at the junction of the basilar and left posterior cerebral arteries could not be determined.

Dissecting aneurysm of the basilar artery $[1,2]$ and oral contraceptives [11] have been suggested as causes of vertebrobasilar artery thrombosis in young adults.

The etiology of the vertebrobasilar occlusive disease in our three cases remains unproven. The role of the slightly prolonged partial thromboplastin and thrombin times in Case 1 and of the platelet abnormality in Case 2 is uncertain. DeVivo [3] considered a hypercoagulable state as a possible cause of basilar artery thrombosis in a 10 year old child. Carotid arteritis secondary to a nonspecific upper respiratory infection has been suspected as one cause of acute hemiplegia in childhood [6]. Although there was a history of mild cough preceding the onset of thrombosis in Case 1, and "flu" was initially suspected in Case 2, the role of infection in these cases remains unclear. There certainly was no angiographic evidence of vascular abnormality involving the carotid arterial system in any of our three cases.

Head trauma prior to the onset of neurological symptoms was documented in Cases 2 and 3 . It is well known that trauma to the head frequently is associated. 


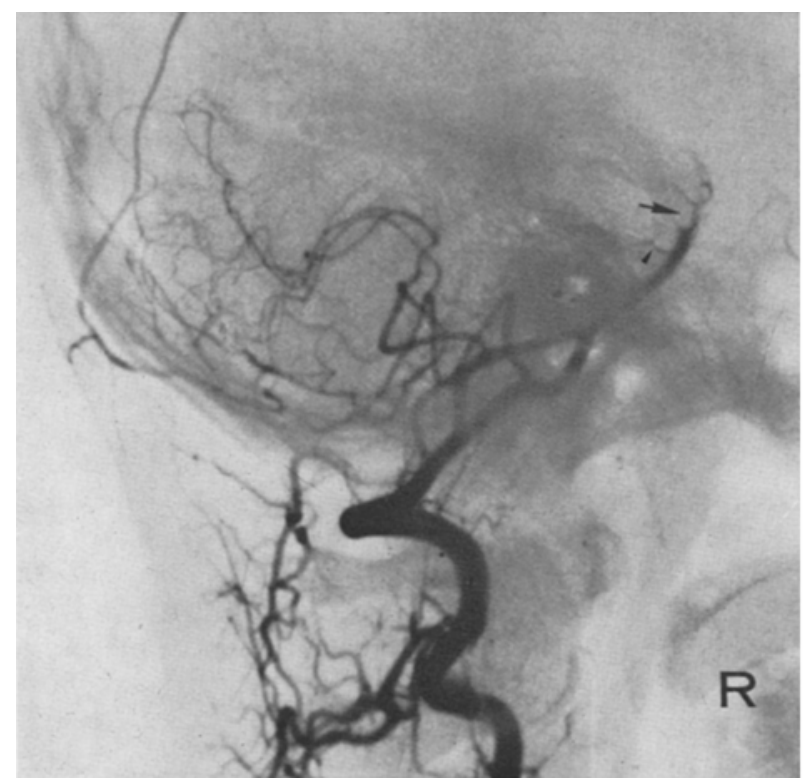

a

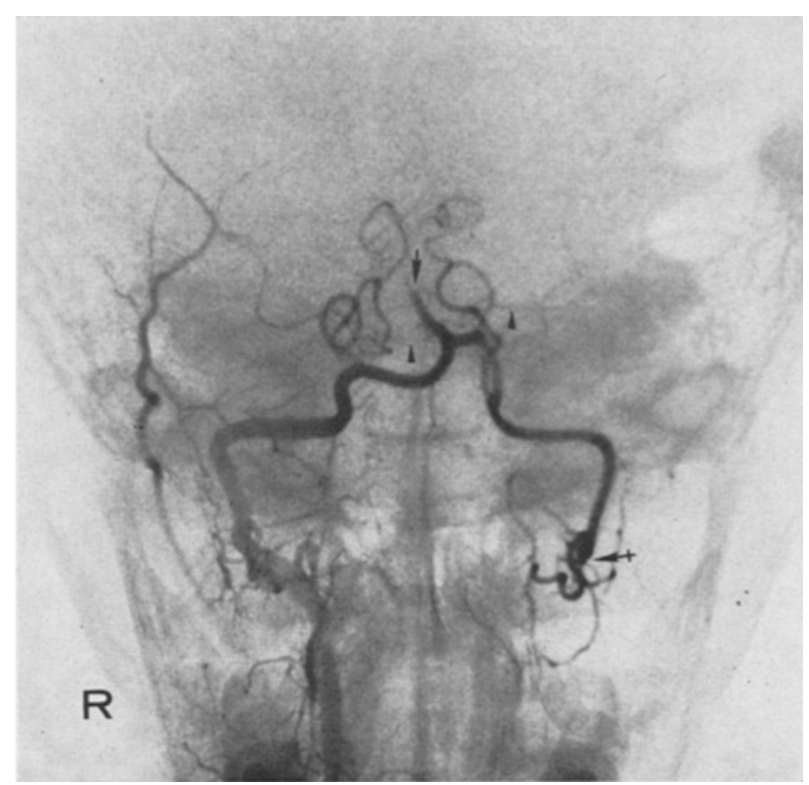

$\mathrm{b}$

Fig. 2. a and b) Selective right vertebral angiogram, lateral and frontal views. There is occlusion of the basilar artery with an intravascular filling defect (arrow) just beyond the origins of the anterior inferior cerebellar arteries (arrowheads). Note reflux into the distal left vertebral artery with abrupt termination at the $\mathrm{C}_{2}$ level (crossed arrow). c) Venous phase. Lack of clearing of contrast from the distal left vertebral artery (arrows) confirms the presence of a more proximal occlusion. d) Right internal carotid angiogram, frontal view. There is irregular narrowing of the proximal left posterior cerebral artery (arrow). The left posterior communicating artery, seen in left carotid ang'iogram, was small (not illustrated). The distal basilar and both superior cerebellar arteries (crossed arrows) fill from the right posterior communicating artery. e) Lateral view. Both superior cerebellar arteries (crossed arrows) and the right poste. rior cerebral artery (arrow) are opacified, with narrowed branches of the latter vessel (arrowheads). The left posterior cerebral artery showed similar involvement. There was collateral filling of peripheral branches of both posterior cerebral arteries (not illustrated)

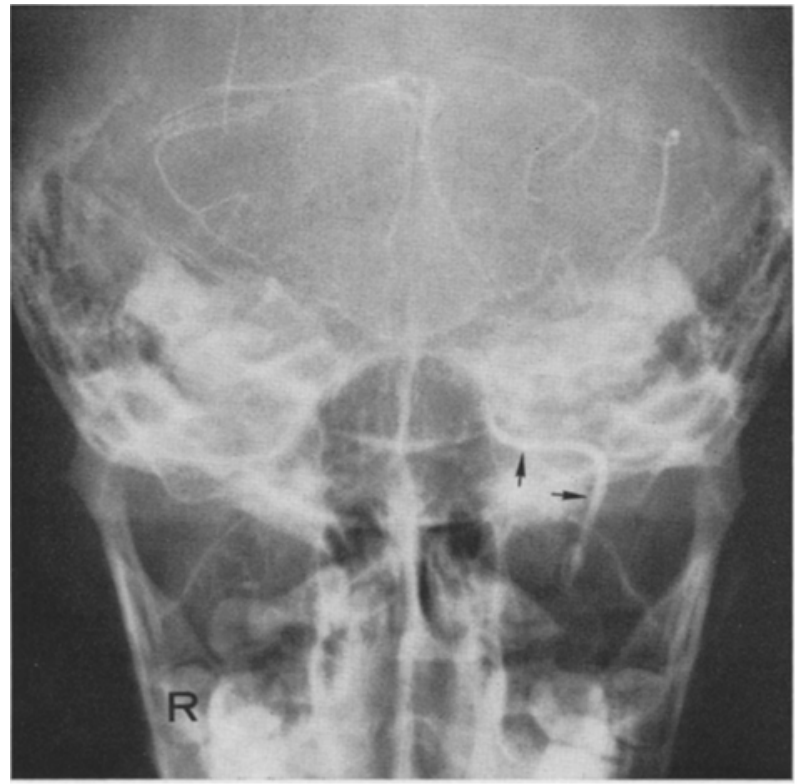

c

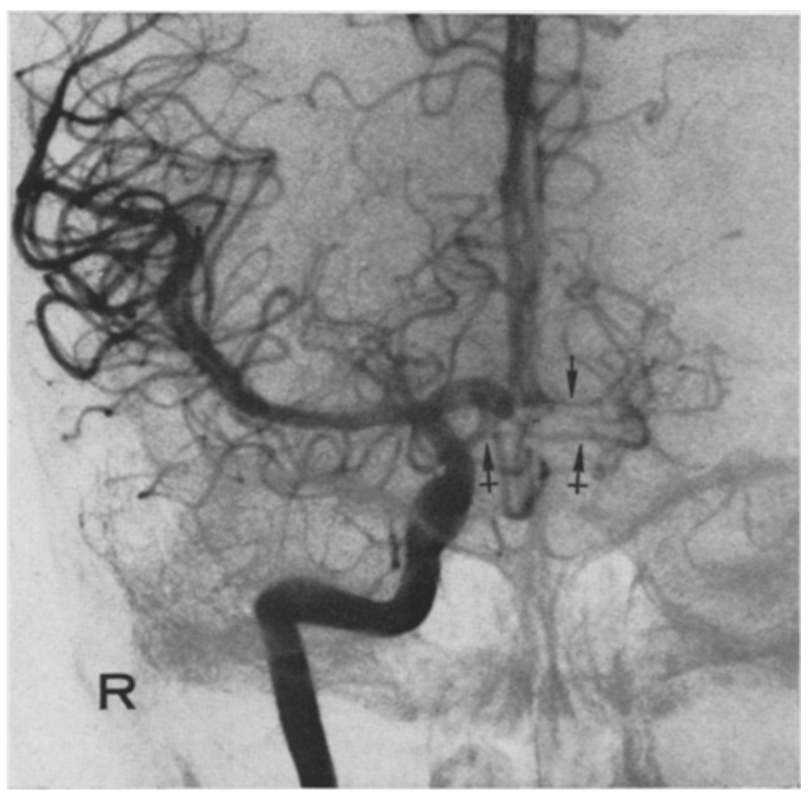

d 


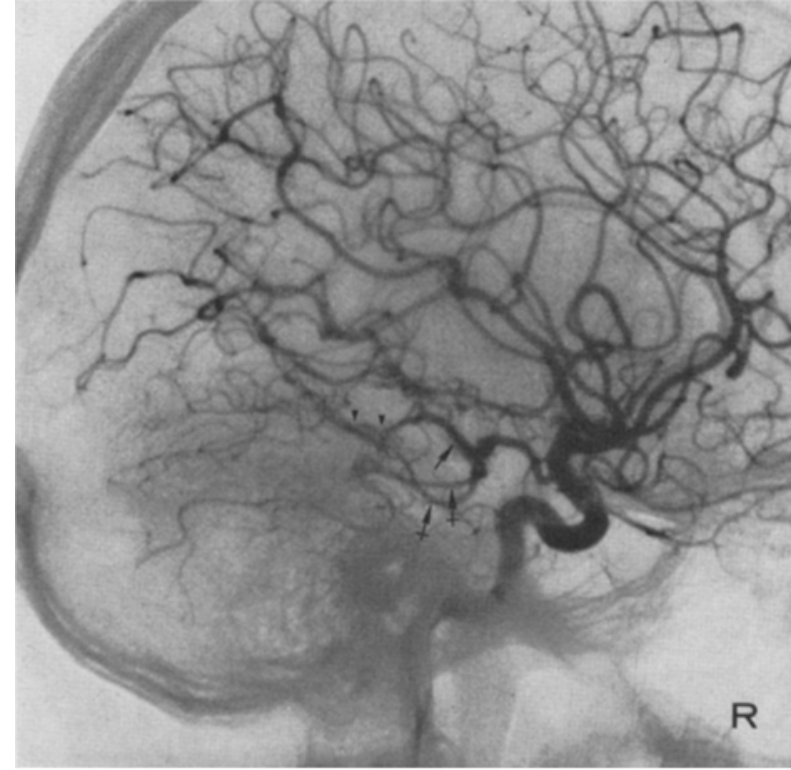

with ligamentous and/or bony injuries of the cervical spine. As the vertebral artery passes between the foramina transversaria of the atlas and axis, it is subjected to considerable motion when the head is rotated toward the opposite side [14]. In our three cases angiography showed an abnormality of at least one vertebral artery at the atlantoaxial level in addition to basilar artery occlusion (Figs. $1 \mathrm{c}$ and $\mathrm{d}, 2 \mathrm{~b}$ and $\mathrm{c}$, and $3 \mathrm{~b}$ and $\mathrm{d}$ ).

It seems quite possible that the vertebral artery could suffer intimal damage or intramural hemorrhage during sudden, marked rotation of the atlas on the axis. This concept is supported by the fact that basilar artery occlusion with associated vertebral artery abnormalities has been reported secondary to chiropractic manipulation of the cervical spine in young adults $[7,8]$. Such cases, including two patients seen by us, show angiographic features which are strikingly similar to those reported in the present paper. Occlusion of the basilar artery and its branches could be readily explained on the basis of embolization from an intimal injury of a vertebral artery.

In an attempt to assess the status of the vertebral arteries in the previous ten cases of angiographically confirmed basilar artery thrombosis in children, two cases were excluded because the cervical portions of the vertebral arteries were not demonstrated $[9,12]$. Of four patients who had normal vertebral arteries $[4$, $10,13,15]$, one had presumed embolization due to a known bacterial endocarditis [10]. The four remaining cases showed definite abnormalities of one or both vertebral arteries at the altantoaxial level $[3,6,10]$. One of the latter cases had a history of antecedent head injury [10].

Other etiologies which should be considered in cases of sudden or spontaneous basilar artery throm- bosis in children and young adults include underlying cardiac disease (particularly bacterial endocarditis), arteritis, meningitis, blood abnormalities with clotting disorders, collagen diseases and connective tissue diseases. A combination of causes may be responsible in certain cases, and some of these etiologies may be contributing factors in the presence of trauma.

Basilar artery thrombosis may often be suspected or even diagnosed conclusively by carotid angiography. However, vertebral angiography will usually provide a more reliable diagnosis. A combination of carotid and vertebral angiography will provide the most complete assessment, not only of the occlusive disease but also of the available collateral flow. The angiographic criteria of basilar artery thrombosis have been described by previous authors $[1,9,12,16]$.

Although vertebrobasilar artery thrombosis is rare in childhood, increasing familiarity with the clinical syndrome and greater availability of high quality and safe, complete cerebral angiography will probably lead to its more frequent and earlier recognition. The present study suggests that such patients should be investigated by complete angiography of the vertebrobasilar system, including the cervical portions of the vertebral arteries. Accurate demonstration and localization of all the vascular abnormalities hopefully will help to clarify the presumed multiple etiologies, including the suspected importance of trauma.

\section{Addendum}

Since submitting this paper for publication, we have studied a 6 year old boy with sudden, apparently spontaneous basilar artery thrombosis. Complete cerebral angiography revealed focal narrowing of the left vertebral artery at the $\mathrm{C}_{2}$ level with adjacent dilatation strongly suggestive of pseudoaneurysm, and with occlusion of the basilar artery just proximal to the origins of the superior cerebellar arteries. Both posterior cerebral arteries and the left superior cerebellar artery filled from the left posterior communicating artery. The right superior cerebellar artery was occluded at its origin. There was no history of antecedent trauma and cerebrospinal fluid and blood studies were normal. The patient had recovered from measles one week before his occlusive episode.

\section{References}

1. Brihaye, J., Retif, J., Jeanmart, L.: L'obstruction de l'artère basilaire chez le sujet jeune. Aspects cliniques et angiographiques. Réflexions étio-pathogéniques. A propos de trois cas. Acta neurochir. (Wien) 24, 143$156(1971)$

2. Brihaye, J., Retif, J., Jeanmart, L., Flament-Durand, J.: Occlusion of the basilar artery in young pa. tients. Acta neurochir. (Wien) 25, 225-229 (1971)

3. DeVivo, P.C., Farrell, F.W.: Vertebrobasilar occlusive disease in children. A recognizable clinical entity. Arch. Neurol. (Chic.) 26, 278-281 (1972) 


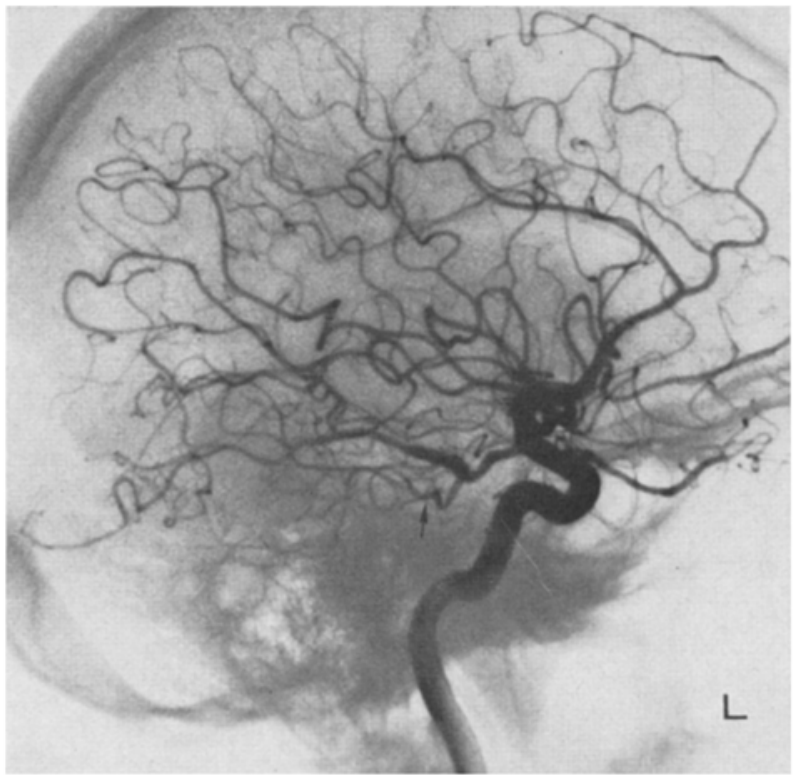

a

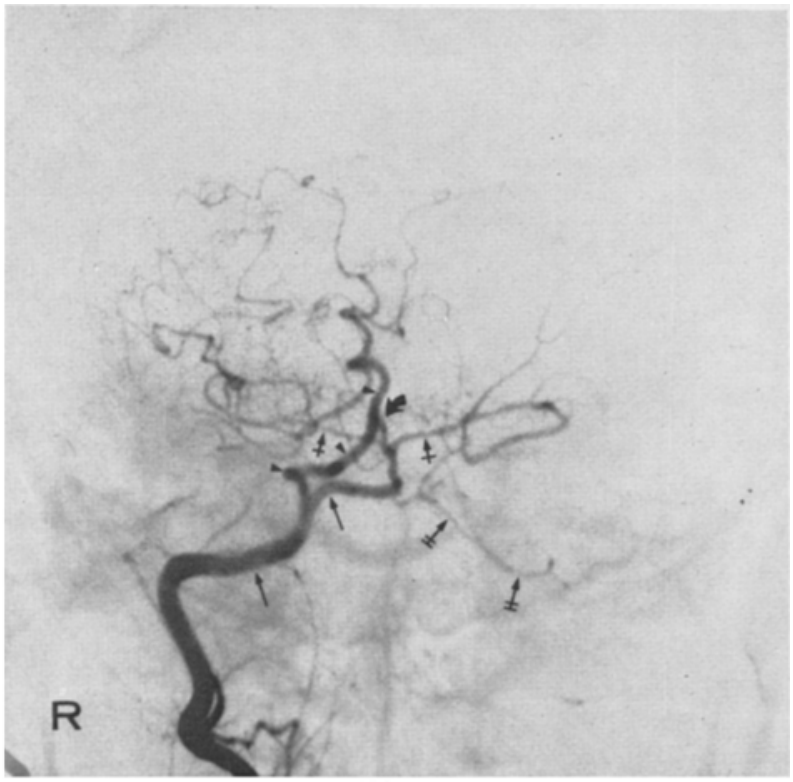

b

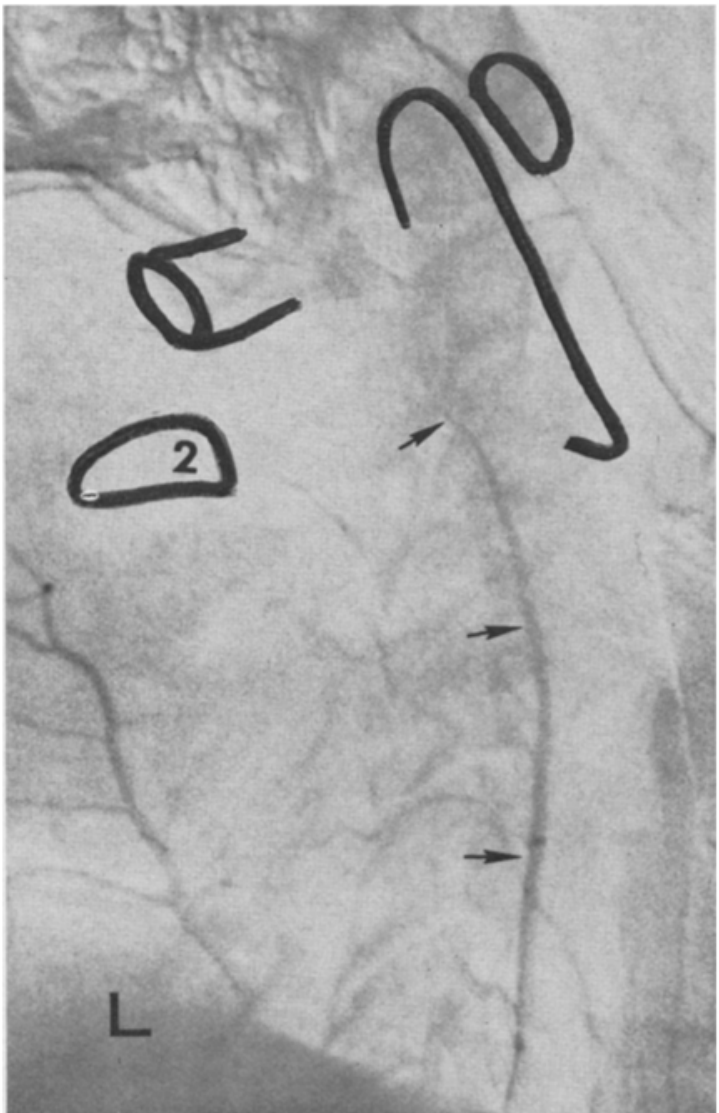

Fig. 3. a) Left internal carotid angiogram. The left posterior cerebral artery and left superior cerebellar artery (arrow) are filled from the left posterior cornmunicating artery. A large right posterior communicating artery seen in the right carotid angiogram (not illustrated) supplied only the right posterior cerebral artery. b. and c) Selective right vertebral angiogram, frontal and lateral views. The basilar artery is small and nearly occluded (curved arrow) distal to the origins of the anterior inferior cerebellar arteries (crossed arrows). Reflux of contrast from the right vertebral artery (arrows) into the left (double-crossed arrows) terminates at the $\mathrm{C}_{1}$ level. $A$ large right posterior inferior cerebellar artery (arrowheads) supplies both inferior vermian branches and much of the territory of the oceluded right superior cerebellar artery. d) Left subclavian injection. The left vertebral artery (arrows) fills only to the $\mathrm{C}_{2}$ level 
4. Dooley, J.M., Smith, K.R.: Occlusion of the basilar artery in a 6 year old boy. Neurology 18, 1034-1036 (1968)

5. Fowler, M.: Two cases of basilar artery occlusion in childhood. Arch. Dis. Childh. 37, 78-81 (1962)

6. Harwood-Nash, D.C., McDonald, P., Argent, W.: Cerebral arterial disease in children. An angiographic study of 40 eases. Amer. J. Roentgenol. 111, 672-686 (1971)

7. Kanshepolsky, J., Danielson, H., Flynn, R. E.: Vertebral artery insufficiency and cerebellar infarct due to manipulation of the neck. Bull. Los Angeles neurol. Soc. 37, 62-66 (1972)

8. Lorenz, R., Vogelsang, H.-G.: Thrombose der Arteria basilaris nach chiropraktischen Manipulationen an der Halswirbelsäule. Dtsch. med. Wschr. 97, 36-43(1972)

9. Moscow, N.P., Newton, T.H.: Angiographic implications in diagnosis and prognosis of basilar artery occlusion. Amer. J. Roentgenol. 119, 597-604 (1973)

10. Ouvrier, R.A., Hopkins, I.J.: Occlusive disease of the vertebrobasilar arterial system in childhood. Develop Med. Child Neurol. 12, 186-192 (1970)

11. Pochaczersky, R., Uygur, Z., Berman, A.J.: Basilar artery occlusion. J. Canad. Assoc. Radiol. 22, $261-263$ (1971)

12. Schechter, M.M., Zingesser, L.H.: The radiology of basilar thrombosis. Radiology 85, 23-32 (1965)

13. Thibaut, A., Thiry, S.: L'oblitération de l'artére basilaire. Neurochirurgie 9, 66-74 (1962)

14. Toole, J.F., Tucker, S.H.: Influence of head position upon cerebral circulation. Studies on blood flow in cadavers. Arch. Neurol. (Chic.) 2, 616-623 (1960)

15. Ulbricht, von W., Porstmann, W.: Zu Klinik und Angiogramm des thrombotischen Basilarisverschlus. ses. Psychiat. Neurol. med. Psychol. (Lpz.) 13, 299302 (1961)

16. Weidner, W., Crandall, P., Hanafee, W., Tomiyasu, V.: Collateral eirculation in the posterior fossa with leptomeningeal anastomoses. Amer. J. Roentgenol. $\mathbf{9 5}, 831-836(1965)$

Joachim F. Seeger, M.D.

Dept. of Radiology

University of Michigan

Medical Center

Ann Arbor, Mich. 48104

USA 